\title{
KONTRIBUSI LOCUS OF CONTROL DAN KEPUASAN KERJA TERHADAP KOMITMEN ORGANISASI KARYAWAN WARALABA DI KOTA MANADO
}

\author{
Shinta Nento \\ Fakultas Ilmu Tarbiyah dan Keguruan IAIN Manado \\ Email: shintanento@iain-manado.ac.id
}

\begin{abstract}
This study aims to examine and measure the contribution of locus of control and job satisfaction to organizational commitment among employees of a franchise that is currently popular in Manado City. The research used survey method with quantitative approach, measurement and structural equation modeling (SEM) testing using SmartPLS 3.2 software. The results showed that locus of control and job satisfaction contributed positively and indirectly to employee organizational commitment. Based on the research findings, it can be taken in the recruitment process to consider the locus of control and job satisfaction values of prospective employees.
\end{abstract}

Keywords: Locus of Control, Job Satisfaction, and Organizational Commitment

\begin{abstract}
ABSTRAK
Penelitian ini bertujuan menguji dan mengukur kontribusi locus of control dan kepuasan kerja terhadap komitmen organisasi pada karyawan salah satu waralaba yang sedang populer di Kota Manado. Penelitian dengan metode survei pendekatan kuantitatif, pengukuran dan pengujian Structural Equation Modeling (SEM) menggunakan software SmartPLS 3.2. Hasil penelitian menunjukkan bahwa locus of control dan kepuasan kerja berkontribusi positif dan signifikan secara langsung ataupun tidak langsung terhadap komitmen organisasi karyawan. Berdasarkan temuan penelitian, maka dapat direkomendasikan dalam proses perekrutan karyawan mempertimbangkan nilai locus of control dan nilai kepuasan kerja calon karyawan.
\end{abstract} Kata kunci: Locus of Control, Kepuasaan Kerja, dan Komitmen Organisasi

\section{PENDAHULUAN}

Komitmen organisasi diartikan sejauh mana karyawan percaya dan menerima tujuan organisasi dan keinginan untuk tetap bersama organisasi (Muthuveloo \& Rose, 2005). Demikian pula didefinisikan bahwa komitmen organisasi sebagai bentuk identifikasi diri karyawan terikat dengan organisasi (AlJabari \& Ghazzawi, 2019).

Studi telah menunjukkan bahwa komitmen organisasi karyawan meningkatkan efektivitas organisasi melalui kinerja dan kualitas pekerjaan dan rendah tingkat keterlambatan, 
ketidakhadiran, dan turnover (Razzaq et al., 2019). Pengembangan komitmen organisasi antar karyawan dapat ditingkatkan melalui variabel usia, status perkawinan, jenis kelamin, locus of control, dan kepuasan kerja (Churchill et al., 2020). Untuk tujuan penelitian ini, pengaruh locus of control dan kepuasan kerja atas komitmen organisasi menjadi fokus utama.

Komitmen organisasi telah ditentukan oleh berbagai penulis dan peneliti. Secara umum, komitmen organisasi dapat digambarkan sebagai tingkat keterikatan yang dirasakan terhadap organisasi (Gopinath, 2020) tempat seseorang bekerja.

Studi telah menunjukkan bahwa komitmen organisasi sebagai sebuah konstruksi dengan dimensinya sebagai kekuatan identifikasi keterlibatan individu dalam organisasi tertentu(Al-Jabari \& Ghazzawi, 2019). Menyatakan bahwa komitmen organisasi ada tiga karakteristik: keyakinan yang kuat dalam penerimaan tujuan organisasi dan nilai-nilai; kesediaan untuk mengerahkan upaya yang cukup besar atas nama organisasi; dan, keinginan yang kuat untuk mempertahankan keanggotaan dalam organisasi. Definisi ini menunjukkan bahwa komitmen organisasi adalah keterikatan afektif atau emosional karyawan ke organisasi tempat mereka bekerja (Abdelmoteleb, 2019).

Komitmen organisasi secara luas diakui sebagai konstruksi multidimensi (Afshari et al., 2019). (Battistelli et al., 2019) mendefinisikan organisasi komitmen sebagai keadaan psikologis yang menjadi ciri karyawan berhubungan dengan organisasi dan berimplikasi pada keputusan untuk melanjutkan atau berhenti dari keanggotaan dalam organisasi. Mereka membagi organisasi komitmen menjadi tiga komponen yang berbeda yaitu afektif, kelanjutan, dan komitmen normatif.

Komitmen Afektif mengacu pada keterikatan emosional karyawan dalam organisasi. Karyawan dengan komitmen afektif yang kuat untuk melanjutkan pekerjaan dengan organisasi karena mereka ingin melakukannya (Bouraoui et al., 2019). Komitmen berkelanjutan mengacu pada kesadaran akan biaya yang terkait dengan meninggalkan organisasi. Karyawan yang tautan utamanya ke organisasi didasarkan pada kelanjutan tetap karena mereka perlu melakukannya (Nasab \& Afshari, 2019). Komitmen normatif mengacu pada perasaan berkewajiban untuk melanjutkan pekerjaan. Karyawan dengan komitmen normatif tinggi merasakan tetap bersama 
organisasi dan komponen komitmen mempengaruhi perilaku karyawan (Potgieter et al., 2019).

Terlepas dari kenyataan bahwa terdapat banyak konseptualisasi yang berbeda dari komitmen organisasi, secara umum disepakati komitmen adalah keadaan psikologis yang mempengaruhi karyawan saat berhubungan dengan organisasi dan tindakan selanjutnya termasuk keputusan untuk tetap dengan organisasi (Lambert et al., 2020).

Studi telah menunjukkan bahwa komitmen organisasi karyawan bisa jadi dipengaruhi oleh sejumlah variabel. Variabel ini telah dijelaskan sebagai determinan atau anteseden komitmen organisasi dalam literatur. Misalnya, (Giauque \& Varone, 2019) menyoroti determinan organisasi komitmen sebagai variabel pribadi, organisasi, dan nonorganisasi. Mereka menjelaskan lebih lanjut bahwa: Variabel pribadi termasuk usia, masa kerja dalam organisasi sebagai atribut internal atau eksternal. Variabel organisasi meliputi desain pekerjaan, nilai, dan gaya kepemimpinan seseorang. Variabel non-organisasi mengacu pada ketersediaan alternatif setelah membuat pilihan untuk bergabung dengan suatu organisasi.

Peneliti lainnya melakukan penelitian tentang bagaimana tempat kerja, biografi, dan faktor motivasi mempengaruhi komitmen organisasi karyawan (Gheitani et al., 2019). Hasil penelitian mengungkapkan bahwa ada signifikan perbedaan dalam komitmen organisasi berdasarkan status perkawinan, motivasi kerja, dan pekerjaan mereka masa jabatan. dan, tidak terdapat perbedaan yang signifikan dalam organisasi komitmen berdasarkan tempat kerja dan keyakinan agama.

Selanjutnya, variabel Locus of control merupakan variabel kepribadian yang mengacu pada persepsi individu penyebab utama peristiwa dalam hidup (Asante \& Affum-Osei, 2019). Locus of control dapat dibagi menjadi locus of control internal dan locus of control external. Individu dengan locus of control internal mereka percaya bahwa mereka memiliki kendali atas takdir mereka (Kay et al., 2020).

Mereka cenderung yakin bahwa keterampilan, kemampuan, dan upaya mereka sendiri yang menentukan sebagian besar pengalaman hidup mereka. Sementara individu yang memiliki locus of control external mereka percaya bahwa takdir mereka dikendalikan oleh kekuatan eksternal seperti keberuntungan, peluang, nasib, atau orang lain yang berkuasa (Liang et al., 2019). 
Beberapa studi telah dilakukan tentang pengaruh locus of control pada komitmen organisasi. (Khushk, 2019) mengungkapkan bahwa mereka yang memiliki locus of control internal lebih berkomitmen untuk organisasinya masingmasing daripada mereka yang memiliki locus of control external. Demikian pula, (Mulyani et al., 2019) melaporkan bahwa individu yang memiliki locus of control internal yang cenderung lebih berkomitmen untuk organisasi mereka dibandingkan mereka yang memiliki locus of control external.

Locus of control berasal dalam teori pembelajaran sosial. Kepribadian mendalilkan bahwa perilaku adalah fungsi dari harapan dan nilai penguatan dalam situasi tertentu. Nilai penguatan adalah derajat kesukaan terhadap suatu. Harapan merupakan penguatan tertentu sebagai akibat dari perilaku individu (Rumjaun \& Narod, 2020). Potensi perilaku tertentu terjadi sebagai fungsi dari harapan mengikuti perilaku (Fouragnan et al., 2019).

Locus of control mengacu pada sejauh mana seseorang percaya bahwa peristiwa dalam hidup seseorang bergantung pada perilakunya (Ajzen, 2020). Menurut konstruk locus of control internal, orang-orang dengan harapan internal percaya bahwa perilaku mereka sendiri menentukan sesuatu yang mereka terima. Seseorang dengan atribut locus of control internal berubah menjadi dirinya sendiri dan tindakannya. Mereka percaya dan bertindak seolah mereka mengontrol masa depan sendiri dan melihat diri mereka secara efektif sebagai agen dalam menentukan terjadinya peristiwa dalam hidup (Chiang et al., 2019).

Sebaliknya, seseorang yang percaya pada locus of control external bahwa kesempatan dan keberuntungan mereka tergantung pada orang lain yang berkuasa, memiliki otoritas social tertentu (O’Connor \& Kabadayi, 2020). Mereka yang memiliki locus of control external lebih menyukai instruksi dalam hidupnya. Para peneliti lain mengukur lokus kendali dengan menggunakan Skala Internal / Eksternal (I-E) dimana skor tinggi mencerminkan lokus kontrol eksternal dan skor rendah mencerminkan locus of control internal (Caliendo et al., 2019).

Variabel lain yang penting untuk penelitian ini adalah kepuasan kerja. Kepuasan kerja, sebagai sebuah konsep akademis, telah menarik perhatian bidang manajemen, psikologi dan praktiktisi (Zhu, 2012). Kepuasan kerja dapat digambarkan sebagai keadaan emosi positif yang dihasilkan dari mengevaluasi pekerjaan seseorang dan ketidakpuasan kerja terjadi ketika harapan ini tidak terpenuhi (M. \& 
Durai, 2017). (Judge et al., 2017) menggambarkan kepuasan kerja sebagai sikap umum individu atas pekerjaan. Seseorang dengan tingkat kepuasan kerja yang tinggi menganggap positif sikap terhadap pekerjaan. (Arunachalam \& Palanichamy, 2017) mendefinisikan kepuasan kerja karyawan sebagai respon afektif terhadap berbagai aspek pekerjaan atau situasi kerja.

Studi telah menunjukkan kepuasan kerja dan komitmen organisasi berbeda tetapi terkait (Liu \& Bellibas, 2018). (De Menezes \& Kelliher, 2017) menyoroti perbedaan dengan menyatakan itu kepuasan kerja terutama berkaitan dengan sikap karyawan terhadap pekerjaan, sedangkan komitmen organisasi terutama berkaitan dengan sikap karyawan bertahan dalam organisasi.

$$
\text { (Asrar-ul-Haq et al., 2017) }
$$
melaporkan bahwa ada hubungan yang kuat antara kepuasan kerja dan komitmen organisasi. Ini menyiratkan bahwa kepuasan kerja dan komitmen organisasi mampu saling mempengaruhi. Penemuan ini menunjukkan bahwa pekerja yang relatif puas dengan pekerjaan mereka kemungkinan besar akan merasa puas berkomitmen pada organisasinya. Sementara di sisi lain, pekerja yang relative kurang berkomitmen untuk organisasi mereka cenderung tidak memiliki kepuasan kerja.

Keputusan untuk tetap bersama atau meninggalkan organisasi pada akhirnya, tercermin dalam statistik absensi dan turnover karyawan. Individu yang tidak puas dengan pekerjaan mereka atau yang tidak berkomitmen pada organisasi lebih cenderung menarik diri dari organisasi baik sesekali karena absensi atau secara permanen (Villanueva-Flores et al., 2017).

(Ćulibrk et al., 2018) berpendapat bahwa tidak ada hubungan yang kuat antara pekerjaan kepuasan dan komitmen organisasi. Ia berpendapat bahwa ada banyak karyawan yang puas dengan pekerjaannya tetapi tidak menyukai organisasi tempat mereka bekerja untuk. Dia menyatakan lebih lanjut bahwa ada orang yang mungkin tidak puas dengan pekerjaan saat ini, tetapi sangat berkomitmen pada organisasi tempat mereka bekerja.

Kepuasan kerja penting dalam mempelajari perilaku organisasi. Berdasarkan (Gheitani et al., 2019) kepuasan kerja adalah sikap, keadaan internal. Lebih lanjut bahwa kepuasan kerja dapat dikaitkan dengan perasaan pencapaian pribadi, baik kuantitatif atau kualitatif. (Igbeneghu \& Popoola, 2011) dalam mendefinisikan kepuasan kerja, 
menyatakan bahwa ada tiga dimensi kepuasan kerja yang diterima secara umum;

Pertama, kepuasan kerja adalah respons emosional terhadap situasi kerja. Tidak mungkin dilihat, itu hanya bisa disimpulkan. Kedua, kepuasan kerja seringkali ditentukan oleh bagaimana hasil yang baik memenuhi atau melebihi harapan. Misalnya, jika organisasi peserta merasa bahwa mereka bekerja lebih keras daripada yang lain tetapi menerima lebih sedikit reward, mereka mungkin akan bersikap negative terhadap pekerjaan, atasan, dan atau rekan kerja. Jika mereka merasa diperlakukan dengan sangat baik dan dibayar secara adil, mereka cenderung memiliki sikap positif terhadap pekerjaan. Ketiga, kepuasan kerja mewakili beberapa sikap terkait karakteristik penting dari suatu pekerjaan seperti pekerjaan itu sendiri, gaji, promosi peluang, pengawasan, dan rekan kerja.

Studi telah menunjukkan kepuasan kerja dapat dipengaruhi oleh beberapa faktor. Faktor-faktor ini telah dengan berbagai cara dijelaskan dalam literatur sebagai penyebab atau anteseden. Misalnya, (Judge et al., 2020) menyoroti faktor-faktor yang mempengaruhi kepuasan kerja pekerja: Faktor individu seperti kepribadian, pendidikan, kecerdasan / kemampuan, usia, status perkawinan, orientasi bekerja dan sebagainya. Faktor sosial seperti hubungan dengan rekan kerja, kerja kelompok dan norma, kesempatan untuk berinteraksi dan organisasi informal. Faktor budaya yang mendasari sikap, keyakinan dan nilai. Faktor organisasi seperti sifat dan ukuran, struktur formal, personalia kebijakan dan prosedur, hubungan karyawan, sifat pekerjaan, teknologi dan organisasi kerja, supervisi dan gaya kepemimpinan, manajemen sistem dan kondisi kerja. Serta faktor lingkungan seperti ekonomi, sosial, politik, dan kekuasaan.

Selain itu, (Sobaih \& Hasanein, 2020) menyatakan bahwa faktor lain yang mempengaruhi kepuasan kerja adalah faktor motivasi Herzberg. Teori dua faktor Herzberg dari kepuasan kerja menyoroti faktor-faktor yang menyebabkan kepuasan dan ketidakpuasan kerja. Faktor-faktor yang mengarah pada kepuasan termasuk pengakuan atas pencapaian, pekerjaan dirinya sendiri, dan kemajuan. Faktorfaktor yang menyebabkan ketidakpuasan meliputi kebijakan dan administrasi organisasi, pengawasan, penggajian, dan interpersonal hubungan. Karyawan yang sangat puas pekerjaan mereka lebih kecil kemungkinannya untuk berhenti dari pekerjaan mereka, absen dari pekerjaan (Mongey \& Weinberg, 2020). Karyawan yang tidak puas lebih cenderung kritis 
terhadap supervisor atau rekan kerja mereka. Dikatakan lebih jauh bahwa karyawan yang tidak puas dengan gaji atau kondisi kerja mereka dapat bergabung sebagai serikat pekerja dan melakukan pemogokan(Wu \& Wu, 2019).

\section{METODE}

Penelitian ini menggunakan metode survei dengan pendekatan kuantitatif. Menjelaskan hubungan kausal dan pengujian hipotesis. Penelitian survei ini digunakan dengan maksud menjelaskan hubungan kausal dan pengujian hipotesis, serta prediksi atau meramalkan kejadian(Riduwan \& Engkos Ahmad Kuncoro, 2007).

Pengukuran dan pengujian model struktural penelitian menggunakan bantuan software SmartPLS 3.2, yang terdiri dari dua sub model yaitu model pengukuran (measurement model) atau outer model dan model struktural (structural model) atau inner model (Ghozali, 2015).

Populasi dalam penelitian ini adalah seluruh karyawan dari salah satu minimarket waralaba di Kota Manado. Teknik yang digunakan dalam penarikan sampel penelitian dengan teknis simple random sampling acak tanpa memperhatikan strata (tingkatan) anggota populasi karena dianggap telah homogen.
Teknik pengumpulan data dengan angket. Angket atau instrumen penelitian berasal dari penjabaran variabel locus of control, kepuasan kerja dan komitmen organisasi. Masing-masing instrumen dari setiap variabel di atas dilakukan validitas logis dan konstruk. Validitas logis untuk memastikan instrumen yang digunakan andal, sementara validitas konstruk dengan uji butir melalui software SPSS. Sedangkan reliabilitas instrumen untuk memastikan bahwa instrumen selalu stabil digunakan berulang dan konsisten dalam menjaring data. Adapun skala yang digunakan adalah skala likert yakni pilihan paling rendah sampai pilihan paling tinggi yakni skala $1-5$. Variable dan kisi-kisi instrument penelitian sebagaimana tabel berikut:

\section{Tabel 1 Variabel dan Indikator Penelitian}

\begin{tabular}{|c|c|}
\hline Variabel & Indikator \\
\hline \multirow{3}{*}{$\begin{array}{l}\text { Locus of control } \\
\text { (X1) }\end{array}$} & Percaya diri \\
\hline & $\begin{array}{l}\text { Bekerja sungguh- } \\
\text { sungguh }\end{array}$ \\
\hline & $\begin{array}{l}\text { Puas tanpa bantuan } \\
\text { orang }\end{array}$ \\
\hline \multirow{3}{*}{$\begin{array}{l}\text { Kepuasan kerja } \\
\text { (X2) }\end{array}$} & Supervisor \\
\hline & Rekan kerja \\
\hline & Gaii \\
\hline
\end{tabular}




\begin{tabular}{|ll|}
\hline \multirow{2}{*}{ Komitmen } & $\begin{array}{l}\text { Menerima norma } \\
\text { organisasi }\end{array}$ \\
\cline { 2 - 2 } organisasi (Y) & Mematuhi aturan \\
\cline { 2 - 2 } & $\begin{array}{l}\text { Merasa bangga atas } \\
\text { pekerjaan }\end{array}$ \\
\hline
\end{tabular}

Teknik analisis data menggunakan bantuan software pengolah data yakni software excel for windows untuk tabulasi data, SPSS 17 for windows digunakan sebagai alat analisis deskriptif dan adapun SmartPLS 3.2 untuk evaluasi sekaligus pengujian model penelitian. Analisis data penelitian dilakukan analisis model pengukuran beserta hasil model struktural.

Angket diedarkan kepada 100 responden target berbentuk angket (pertanyaan terstruktur dan tertutup). Angket kembali berjumlah 89 angket. Jumlah angket kembali masih memenuhi rasio sebagaimana idealnya sampel yang diprasyaratkan alat analisis statistik yakni SmartPLS 3.2. Adapun paradigma penelitian sebagaimana gambar berikut:

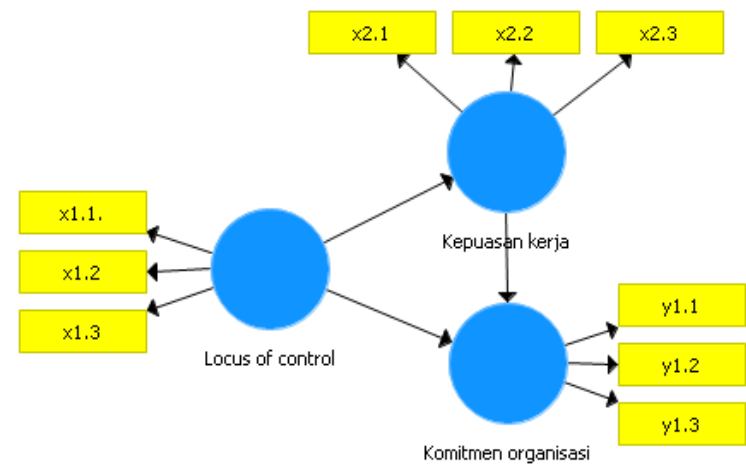

Gambar 1. Paradigma Penelitian

\section{HASIL PENELITIAN \\ Evaluasi Outer Model}

Dalam model PLS SEM convergent validity dikatakan valid jika nilai loading di atas 0.5 untuk menjelaskan kemampuan indikator menggambarkan konstruknya. Table berikut menampilkan nilai convergent validty dalam penelitian ini.

Tabel 1. Convergent Validity

\begin{tabular}{|c|c|c|}
\hline Variabel & Indikator & $\begin{array}{l}\text { Outer } \\
\text { Loading }\end{array}$ \\
\hline \multirow{3}{*}{$\begin{array}{l}\text { Locus of } \\
\text { control } \\
\text { (X1) }\end{array}$} & Percaya diri & 0.856 \\
\hline & $\begin{array}{l}\text { Bekerja sungguh- } \\
\text { sungguh }\end{array}$ & 0.869 \\
\hline & $\begin{array}{l}\text { Puas tanpa } \\
\text { bantuan orang }\end{array}$ & 0.795 \\
\hline \multirow{3}{*}{$\begin{array}{l}\text { Kepuasan } \\
\text { kerja } \\
\text { (X2) }\end{array}$} & Supervisor & 0.848 \\
\hline & Rekan kerja & 0.751 \\
\hline & Gaji & 0.911 \\
\hline \multirow{4}{*}{$\begin{array}{l}\text { Komitmen } \\
\text { organisasi } \\
\text { (X3) }\end{array}$} & $\begin{array}{l}\text { Menerima norma } \\
\text { organisasi }\end{array}$ & 0.801 \\
\hline & Mematuhi aturan & 0.843 \\
\hline & $\begin{array}{l}\text { Memprioritaskan } \\
\text { pekerjaan }\end{array}$ & 0.874 \\
\hline & $\begin{array}{l}\text { Merasa bangga } \\
\text { atas pekerjaan }\end{array}$ & 0.364 \\
\hline \multicolumn{3}{|c|}{$\begin{array}{l}\text { Di samping uji validitas konstruk, } \\
\text { dilakukan juga uji reliabilitas konstruk } \\
\text { dengan maksud mengukur internal } \\
\text { konsistensi dengan ketentuan bahwa nilai }\end{array}$} \\
\hline
\end{tabular}


Berikut ini nilai composite reliability hasil pengujian.

Tabel 2. Composite Reliability

\begin{tabular}{|lc|}
\hline Variabel & $\begin{array}{c}\text { Composite } \\
\text { Reliability }\end{array}$ \\
\hline Locus of control & 0.878 \\
\hline Kepuasan kerja & 0.877 \\
\hline $\begin{array}{l}\text { Komitmen } \\
\text { organisasi }\end{array}$ & 0.878 \\
\hline
\end{tabular}

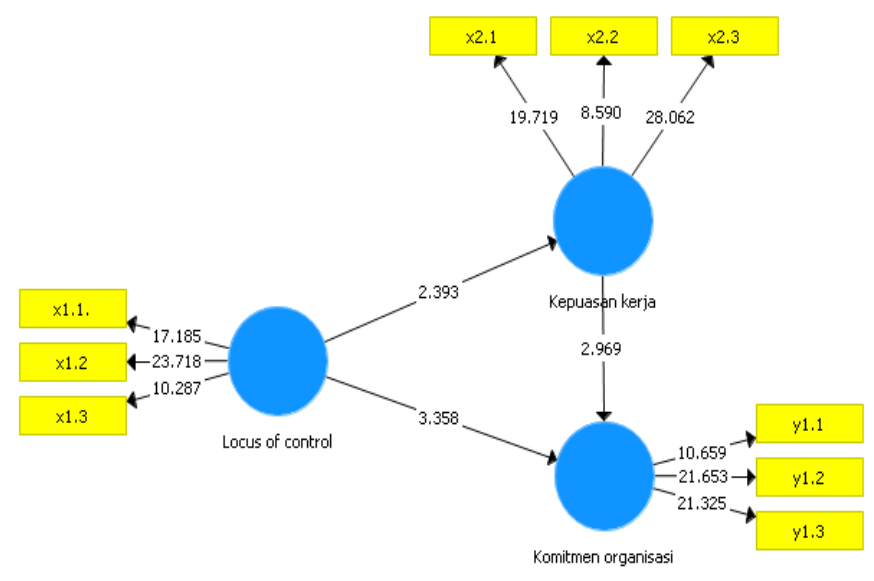

Berdasarkan tabel 2 di atas bahwa nilai composite reliability baik konstruk locus of control, kepuasan kerja dan komitmen organisasi semuanya di atas 0.7. Maka dapat disimpulkan bahwa keseluruhan konstruk memiliki reliabilitas memadai.

\section{Evaluasi Inner Model}

Uji model dilakukan untuk mengevaluasi kontribusi antar konstruk seperti yang telah dihipotesiskan. Hasil uji model dapat dilihat pada gambar berikut:

\section{Gambar 2. Hasil pengujian model penelitian}

Asumsi pengujian model penerimaan ataupun penolakan didasarkan pada nilai $\mathrm{t}_{\text {statistik }}$ dan P-Values. Jika $\mathrm{t}_{\text {statistik }}$ $>$ dari $\mathrm{t}_{\text {tabel }}=1.663$ dan P-Values $<\alpha=$ 0.10, maka Ha diterima dan H0 ditolak. Demikian pula sebaliknya jika $t_{\text {statistik }}<$ dari $\mathrm{t}_{\text {tabel }}=1.663$ dan P-Values $>\alpha=0.10$, maka Ha ditolak dan H0 diterima. Berdasar pada gambar pengujian model di atas, maka dapat diringkas sebagaimana dalam tabel berikut: 
Tabel 3. Hasil Pengujian Model

\begin{tabular}{|c|c|c|c|c|}
\hline No & Konstruk Hipotesis & $\begin{array}{c}\text { Original } \\
\text { Sample (O) }\end{array}$ & $\begin{array}{c}\text { t-statistik } \\
(|\mathrm{O} / \mathrm{STDEV}|)\end{array}$ & $\begin{array}{c}\text { P- } \\
\text { Values }\end{array}$ \\
\hline 1 & Locus of control -> Kepuasan kerja & 0.255 & 2.393 & 0.017 \\
\hline 2 & $\begin{array}{l}\text { Locus of control -> Komitmen } \\
\text { organisasi }\end{array}$ & 0.295 & 3.358 & 0.001 \\
\hline 3 & $\begin{array}{l}\text { Kepuasan kerja -> Komitmen } \\
\text { organisasi }\end{array}$ & 0.275 & 2.969 & 0.003 \\
\hline 4 & $\begin{array}{l}\text { Locus of control -> Kepuasan kerja - } \\
>\text { Komitmen organisasi }\end{array}$ & 0.070 & 1.811 & 0.071 \\
\hline
\end{tabular}

\section{Uji Model Struktural}

Penilaian model struktural dalam SmartPLS dengan melihat nilai R-Square untuk setiap variabel laten dependent.

Tabel 4. Nilai $R$-Square

\begin{tabular}{|c|c|}
\hline Variabel & R-Square \\
\hline Kepuasan kerja & 0.065 \\
\hline Komitmen organisasi & 0.204 \\
\hline
\end{tabular}

Nilai R-Square variable kepuasan kerja sebesar 6.5\%, dan komitmen organisasi sebesar $20 \%$. Besaran perolehan nilai persentase masing-masing variable latent dependent tersebut menunjukkan bahwa setiap variable laten dependent dapat dijelaskan oleh variable dependen locus of control.

Penilaian goodness of fit juga dapat diketahui dari nilai $Q$-Square. Nilai $Q$ Square memiliki arti yang sama dengan coefficient determination ( $R$-Square) pada analisis regresi, dimana semakin tinggi $Q$ Square, maka model dapat dikatakan semakin baik atau semakin fit dengan data. Adapun hasil perhitungan nilai $Q$-Square adalah sebagai berikut:

Q-Square $\quad=1-\left[\left(1-\mathrm{R}^{2} 1\right) \times(1-\right.$ $\left.\mathrm{R}^{2} 2\right)$ ]

$$
=1-[(1-0.065) \times(1-
$$

0.204)]

$$
\begin{aligned}
& =1-(0.935 \times 0.796) \\
& =1-0.744 \\
& =0.25
\end{aligned}
$$

Berdasarkan hasil perhitungan di atas, diperoleh nilai $Q$-Square sebesar 0.25. Hal ini menunjukkan besarnya keragaman dari data penelitian yang dapat dijelaskan oleh model penelitian adalah sebesar $25 \%$. Sedangkan sisanya sebesar $75 \%$ dijelaskan oleh faktor lain yang berada di luar model penelitian ini. 


\section{PENUTUP}

Pertama, penelitian ini memberikan bukti empiris bahwa locus of control memiliki kontribusi signifikan atas kepuasan kerja karyawan. Kedua, penelitian ini memberikan bukti empiris mendukung model teoritis bahwa locus of control memiliki kontribusi positif yang signifikan terhadap komitmen Organisasi. Ketiga, penelitian juga mengkonfrmasi kontribusi kepuasan kerja terhadap komitmen organisasi. Keempat, penelitian juga memberikan bukti kombinasi locus of control melalui kepuasan kerja secara signifikan dapat mempengaruhi komitmen organisasi pegawai alfamart di Kota Manado. Berdasarkan temuan penelitian dapat direkomendasikan bahwa dalam proses perekrutan karyawan dapat mempertimbangkan nilai locus of control dan nilai kepuasan kerja calon karyawan.

\section{DAFTAR PUSTAKA}

Abdelmoteleb, S. A. (2019). A new look at the relationship between job stress and organizational commitment: A three-wave longitudinal study. Journal of Business and Psychology, 34(3), 321-336.

Afshari, L., Young, S., Gibson, P., \& Karimi, L. (2019). Organizational commitment: exploring the role of identity. Personnel Review.
Ajzen, I. (2020). The theory of planned behavior: Frequently asked questions. Human Behavior and Emerging Technologies, 2(4), 314324.

Al-Jabari, B., \& Ghazzawi, I. (2019). Organizational Commitment: A Review of the Conceptual and Empirical Literature and a Research Agenda. International Leadership Journal, 11(1).

Arunachalam, T., \& Palanichamy, Y. (2017). Does the soft aspects of TQM influence job satisfaction and commitment? An empirical analysis. The TQM Journal.

Asante, E. A., \& Affum-Osei, E. (2019). Entrepreneurship as a career choice: The impact of locus of control on aspiring entrepreneurs' opportunity recognition. Journal of Business Research, 98, 227-235.

Asrar-ul-Haq, M., Kuchinke, K. P., \& Iqbal, A. (2017). The relationship between corporate social responsibility, job satisfaction, and organizational commitment: Case of Pakistani higher education. Journal of Cleaner Production, 142, 23522363.

Battistelli, A., Odoardi, C., Vandenberghe, C., Di Napoli, G., \& Piccione, L. (2019). Information sharing and 
innovative work behavior: The role of work-based learning, challenging tasks, and organizational commitment. Human Resource Development Quarterly, 30(3), 361381.

Bouraoui, K., Bensemmane, S., Ohana, M., \& Russo, M. (2019). Corporate social responsibility and employees' affective commitment. Management Decision.

Caliendo, M., Cobb-Clark, D. A., Hennecke, J., \& Uhlendorff, A. (2019). Locus of control and internal migration. Regional Science and Urban Economics, 79, 103468.

Chiang, Y.-T., Fang, W.-T., Kaplan, U., \& $\mathrm{Ng}$, E. (2019). Locus of control: The mediation effect between emotional stability and proenvironmental behavior. Sustainability, 11(3), 820.

Churchill, S. A., Munyanyi, M. E., Prakash, K., \& Smyth, R. (2020). Locus of control and the gender gap in mental health. Journal of Economic Behavior \& Organization, 178, 740-758.

Ćulibrk, J., Delić, M., Mitrović, S., \& Ćulibrk, D. (2018). Job satisfaction, organizational commitment and job involvement: The mediating role of job involvement. Frontiers in Psychology, 9, 132.

De Menezes, L. M., \& Kelliher, C. (2017). Flexible working, individual performance, and employee attitudes: Comparing formal and informal arrangements. Human Resource Management, 56(6), 1051-1070.

Fouragnan, E. F., Chau, B. K. H., Folloni, D., Kolling, N., Verhagen, L., Klein-Flügge, M., Tankelevitch, L., Papageorgiou, G. K., Aubry, J.-F., \& Sallet, J. (2019). The macaque anterior cingulate cortex translates counterfactual choice value into actual behavioral change. Nature Neuroscience, 22(5), 797-808.

Gheitani, A., Imani, S., Seyyedamiri, N., \& Foroudi, P. (2019). Mediating effect of intrinsic motivation on the relationship between Islamic work ethic, job satisfaction, and organizational commitment in banking sector. International Journal of Islamic and Middle Eastern Finance and Management.

Ghozali, I. (2015). Partial Leaast Square, Konsep, Teknik dan Aplikasi Menggunakan Program SmartPLS 3.0. Universitas Diponegoro.

Giauque, D., \& Varone, F. (2019). Work opportunities and organizational 
commitment in international organizations. Public Administration Review, 79(3), 343354.

Gopinath, R. (2020). ROLE ON EMPLOYEES'ATTITUDE IN WORK PLACE.

Igbeneghu, B. I., \& Popoola, S. O. (2011). Influence of locus of control and job satisfaction on organizational commitment: A study of medical records personnel in university teaching hospitals in Nigeria. Library Philosophy and Practice, 2011(AUGUST).

Judge, T. A., Weiss, H. M., KammeyerMueller, J. D., \& Hulin, C. L. (2017). Job attitudes, job satisfaction, and job affect: A century of continuity and of change. Journal of Applied Psychology, $102(3), 356$.

Judge, T. A., Zhang, S. C., \& Glerum, D. R. (2020). Job satisfaction. Essentials of Job Attitudes and Other Workplace Psychological Constructs, 207-241.

Kay, K., Rogger, D., \& Sen, I. (2020).

Bureaucratic locus of control. Governance, 33(4), 871-896.

Khushk, A. A. (2019). Impact of Locus of Control (LOC) and Organizational Commitment on Employee
Performance-Study of Service Sector, Pakistan. International Journal of Law and Peace Works, 6(5), 1-6.

Lambert, E. G., Keena, L. D., Leone, M., May, D., \& Haynes, S. H. (2020). The effects of distributive and procedural justice on job satisfaction and organizational commitment ofcorrectional staff. The Social Science Journal, 57(4), 405-416.

Liang, S., Chang, Y., Dong, X., \& Wang, J. (2019). Perceived uniqueness: Locus of control, social exclusion, and choice. Social Behavior and Personality: An International Journal, 47(11), 1-7.

Liu, Y., \& Bellibas, M. S. (2018). School factors that are related to school principals' job satisfaction and organizational commitment. International Journal of Educational Research, 90, 1-19. M., S., \& Durai, S. (2017). A study on the impact of Job Satisfaction on Job Performance of Employees working in Automobile Industry, Punjab, India. Journal of Management Research, $9(1), \quad 117$. https://doi.org/10.5296/jmr.v9i1.104 20 
Mongey, S., \& Weinberg, A. (2020).

Characteristics of workers in low work-from-home and high personalproximity occupations. Becker Friedman Institute for Economic White Paper.

Mulyani, S. R., Sari, M. W., Sari, V. N., \& Tawakalni, W. (2019). The Effect Locus of Control and Organizational Culture Toward Employee Performance with Organizational Commitments as Intervening Variable. JEMA: Jurnal Ilmiah Bidang Akuntansi Dan Manajemen, 16(2), 147-159.

Muthuveloo, R., \& Rose, R. C. (2005). Typology of organizational commitment. American Journal of Applied Science, 2(6), 1078-1081.

Nasab, A. H., \& Afshari, L. (2019). Authentic leadership and employee performance: mediating role of organizational commitment. Leadership \& Organization Development Journal.

O'Connor, G. E., \& Kabadayi, S. (2020). Examining antecedents of health insurance literacy: the role of locus of control, cognitive style, and financial knowledge. Journal of Consumer Affairs, 54(1), 227-260.

Potgieter, I., Ferreira, N., \& Coetzee, M. (2019). Perceptions of sacrifice, workplace friendship and career concerns as explanatory mechanisms of employees' organisational commitment. SA Journal of Human Resource Management, 17(1), 1-9.

Razzaq, S., Shujahat, M., Hussain, S., Nawaz, F., Wang, M., Ali, M., \& Tehseen, S. (2019). Knowledge management, organizational commitment and knowledge-worker performance. Business Process Management Journal.

Riduwan \& Engkos Ahmad Kuncoro. (2007). Cara Menggunakan dan Memaknai Analisis Jalur (Path Analysis). Alfabeta.

Rumjaun, A., \& Narod, F. (2020). Social Learning Theory-Albert Bandura. In Science Education in Theory and Practice (pp. 85-99). Springer.

Sobaih, A. E. E., \& Hasanein, A. M. (2020). Herzberg's theory of motivation and job satisfaction: Does it work for hotel industry in developing countries? Journal of Human Resources in Hospitality \& Tourism, 19(3), 319-343.

Villanueva-Flores, M., Valle, R., \& Bornay-Barrachina, M. (2017). Perceptions of discrimination and distributive injustice among people 
with physical disabilities. Personnel Review.

Wu, T.-J., \& Wu, Y. J. (2019). Innovative work behaviors, employee engagement, and surface acting: a delineation of supervisor-employee emotional contagion effects. Management Decision.

Zhu, Y. (2012). A review of job satisfaction. Asian Social Science, 9(1), 293-298. https://doi.org/10.5539/ass.v9n1p29 3 